\title{
The Design and Implementation of English Curriculum for Children in Internet+ Times
}

\author{
Ni Xue \\ School of Foreign Studies, Xi'an University, Xi'an 710065, China \\ Keywords: Internet +; children; English course \\ Abstract: There is an obvious difference between preschool English teaching and adult \\ English teaching. They are different in teaching content, teaching form, teaching method \\ and teaching content. For children's English curriculum, the extra-curricular teaching \\ system is more important than the in-class. At present, internet + has already become a \\ kind of tide, and it also provided a platform at the same time. This platform has the huge \\ impetus and the leading function regarding the teaching. In this paper, children's English \\ curriculum design and implementation in Internet + is analyzed.
}

The current craze for English has become a trend. At present, English education is highly recommended in both schools and training institutions. Both domestic and foreign research results show that young children have very strong language learning ability, so how to make children from an early age have more than ordinary language ability is the common aspiration and desire of every parent. It is under the support of this kind of theory that English courses for young children are flourishing everywhere.

\section{Problems in the teaching of English for Young Children.}

At present, there are many kinds of English training courses for children. As far as the author is concerned, the main problems are as follows:

\subsection{Course Design Problems}

Children's English teaching itself is a scientific and rigorous system,which requires us to make an orderly and reasonable layout on the basis of careful study.At present,the curriculum design system of children's English is not reasonable in general.Some of the curriculum design did not take into account the characteristics of children's psychological development at the beginning of the planning,and some textbooks overemphasize theory,especially Grammar Teaching;Some courses are longer than children's learning load.In addition,children's English teaching materials is also a stubborn illness.The emergence of these problems has much to do with our educational and teaching system.First of all,we do not have a complete,strong operational guidance standards for children's English education,which leads to the direct result of curriculum design and implementation of the standard confusion,low access threshold and a lot of course designs and teaching materials with obvious flaws have entered the market.Secondly,we are not strict enough in 
the management of teaching materials,schools and institutions selected some of the teaching materials imported directly from abroad.Although some of their own experts,but not after the formal channels of review.We can not deny that in the preschool,the United Kingdom and the United States and other developed countries are some places worth learning,but how children English textbooks are simply adopted to learn,this approach is suitable for China's Educational Environment That's a big question. Some of these teaching materials are obviously acclimatized and have to be localized.

\subsection{Problems of teaching practice}

There is a big difference between the implementation of English curriculum and teaching for children and General English teaching.First of all,the age of children determines the content of the curriculum, especially the process of implementation should be fully adapted to children's cognitive ability.Secondly,children's English teaching requires teachers who are engaged in education to understand the teaching characteristics of children's children at various stages.Finally,engaging in early childhood English teaching teachers to understand more aspects of early childhood psychology requires more emotional input into the classroom and guide children to experience.From the sensibility,I recognize the process of rational thinking.But at present,although many teachers have been engaged in English education and teaching for many years, they do not have a comprehensive understanding of children's psychology and characteristics.Some teachers only know English knowledge and have only a smattering of knowledge about education,teaching and child psychology.In this way,they are of course difficult to say clearly about the characteristics of early childhood English teaching.Some teachers even think it is easier to teach English to children than to teach English in general.How effective is education in such a teaching environment.This is a very worthy of our thinking about and take seriously.Teachers as the direct expansion of education and teaching,implementer,the level of teaching knowledge and teaching implementation ability directly affect the quality of teaching.However,due to our understanding of the limitations of this issue has not been given due attention, which is an important cause of mixed results in the implementation of English teaching for young children.

\subsection{The lack of an evaluation system}

What kind of evaluation system should be adopted to evaluate the effect of English teaching for children is a matter of opinion.Some people think that children learning English do not need to set any standards,just need to cultivate children's sense of language can.And some people think that since learning,it is necessary to have a criterion,otherwise good or bad in the end how to distinguish.As far as I am concerned,the evaluation system of children's English learning should be diversified,and it is better not to use a single index to measure,or rely on modern advanced science and technology as the evaluation platform to establish an interactive Evaluation Mechanism of sustainable development. But how to build this evaluation system, whether in theory or in practice, has not been a final conclusion. The lack of evaluation system makes children's English learning and education in a dilemma.

\section{Internet + Education Reform In The Era}

Internet + has been widely used and developed in China,and many functions of internet + have been gradually introduced into various fields of social life.In education teaching aspect,the internet + characteristic is displays incisively and vividly.The main trend of the current global education reform is to pay attention to the individuality of the educated individual,to carry out the 
individualized education suited to the individual characteristics, and to emphasize the individualized development of the students. This has much in common with the liberal education, which we now advocate. At present, the more extensive application of multimedia, micro-classes, and so on, these are just information and internet + education under the conditions of the basic application of teaching. The education teaching based on Internet + and the traditional education teaching complement each other and complement each other.

The traditional teaching mode regards teachers as the core and supporting point of education and teaching. Education and teaching under the Internet conditions can be separated from the form of the students' learning,the teacher's teaching is no longer limited by the time and place,the form of education and teaching has been greatly expanded.For Students, Ithis convenience allows them to use campus networks and mobile phones and other tools, anytime, anywhere for learning.At the same time, learning content is no longer rigid and dull,but rich and colorful as well as interesting, which must greatly enhance students' interest in learning and stimulate their desire to learn.

At present, the construction of internet-based curriculum and teaching system has taken shape in foreign countries. At present, many "double first-class" colleges and universities based on the Internet + course teaching system has been able to meet the needs of teachers and students teaching and learning. However, other colleges and universities,due to funding, research capacity and other factors, the pace of building in this area needs to be accelerated.

The development of Internet + also provides a very good platform for children's English curriculum design and implementation.At present,domestic research on this issue is still in its infancy.How to design and implement the English Course for children under the condition of Internet + is not only an educational problem,but also a social problem

\section{Internet+Children's English curriculum design and implementation}

To do a good job in the design and implementation of the English language curriculum for children under the Internet + era.The author believes that it should focus on the following aspects:

\subsection{Optimizing Teaching Methods}

Internet + is both a platform and a technology. In the internet + conditions, the means of education and teaching has been effectively promoted. Children have their own characteristics, which is our planning and design based on the Internet + Children's English curriculum basis and prerequisite. At present, some popular teaching methods at home and abroad can be grafted into the design and implementation of English curriculum for children. In the form of micro classes. For example. Compared with traditional education, micro-teaching has an absolute advantage. Micro-class is generally in the form of short and concise to be presented, it is no matter in the teaching content bearing or curriculum composition are very flexible. Micro-classes in various forms, teachers can focus on a knowledge point through micro-classes, so that students can grasp and learn. The teaching content of the micro-lesson is also quite outstanding, it turns the abstruse knowledge into zero, has the very strong pertinence. In addition, the length of micro-classes are generally controlled within 10 minutes. This is very much in line with children's learning psychology, according to research shows that children's mental concentration time is generally within 10 minutes, more than that time, the learning effect will be greatly reduced

\subsection{To form a professional curriculum design team}

Under the condition of Internet + ,the intercommunication of information breaks the limitation of space-time. Before,we also studied and coordinated to form a professional team to design children 
English curriculum system,but due to the constraints, has not achieved the desired results.Internet + conditions, the exchange of information and communication has been fully protected.At present,there is no professional team for children's English curriculum design in China,which is basically in the state of wandering.We must strive to build a professional team based on Internet +Team members can communicate and communicate in a regular or irregular manner.We share theoretical and practical results and strive to come up with solutions and solutions in the shortest possible time. Implementation details.At the same time,for Children's English curriculum, teaching, evaluation system standards should also be developed simultaneously. We must actively cooperate with the competent education departments, strive for their support, promote the standards we have developed as far as possible within the broad scope,and realize the standardization of the early childhood English education market as soon as possible.

\subsection{Curriculum Implementation}

The design and implementation of English curriculum for children are two closely related processes. In the implementation of children's English course, we should try our best to achieve the synchronization of classroom teaching and extracurricular teaching. Classroom teaching should do a good job in curriculum planning, teaching material selection, curriculum specific explanation, etc. , extracurricular teaching should make full use of various new media terminals. Here, we need to highlight a problem is that we must do a good job in the training of teachers. We've talked about the power of this question before. In the organization and implementation of the English Course for children, we must select professional teachers, train and evaluate the teaching teachers of the English Course for children, so that they have the qualifications for the post and teaching This is a very easy question to overlook. Previously, many parents put the learning effect of children to the teaching material body, attributed to the curriculum body, parents as long as the teacher is patient and meticulous that their teaching is no problem. This is a very wrong perception. Therefore, we should make full efforts in this weak link and do a good job in the preparatory work.

\section{Conclusion}

Children's English teaching is different from other English teaching. It has its own distinct characteristics. English teaching for children is a complicated and arduous work. We must have a clear understanding in our mind. It is a long-term and systematic work to promote the design and implementation of English course for children under the age of Internet + .As an educator, we must be based on the essence, diligent thinking, and courage to practice, and strive to promote the design and implementation of the Internet-based early childhood English curriculum.

\section{References}

[1] Xu Zhifang.Let's talk about how to promote the construction of preschool education information with "Internet +" [J].Good parents,2018 (34)

[2] Li Xianyuan. Research on the development and utilization of kindergarten network resources under the background of "Internet +"[D].Shandong Normal University,2017.

[3] Wang Xiaohui.Research on the Innovation and Development of Kindergarten Education under the Background of Informationization [J].Good Parents, 2018(33)

[4] Ren Yuqin.Analysis of the Influence of Internet Technology on Preschool Education [J].The House of Drama,2015(12)

[5] Jiang Wenru.Some Understandings on the Status Quo and Countermeasures of Early Childhood Education [J]. Basic Education,2014(01)

[6] Feng Weiwei.Innovative Research on Early Childhood Education in the Age of "Internet +" [J].Basic Education,2014 (01) 